\title{
As práticas cotidianas de alfabetização: o que fazem as professoras?*
}

\author{
Eliana Borges Correia de Albuquerque \\ Artur Gomes de Morais \\ Universidade Federal de Pernambuco, Departamento de Psicologia e Orientação Educacionais
}

\author{
Andréa Tereza Brito Ferreira \\ Universidade Federal Rural de Pernambuco, Departamento de Educação
}

\section{Introdução}

Se o ensino da leitura e da escrita sofreu mudanças diversas ao longo da história, nas três últimas décadas variados aspectos têm influenciado e transformado bastante as formas segundo as quais esse ensino tem sido concebido e posto em prática. Fatores como os avanços teóricos na área, mudanças nas práticas sociais de comunicação e o desenvolvimento de novas tecnologias têm forjado novas propostas pedagógicas e a produção de novos materiais didáticos relacionados à alfabetização inicial e ao ensino de línguas em geral.

No contexto brasileiro, vivemos desde o início da década de 1980 um amplo debate sobre esses temas. Pesquisadores com formação em distintos campos psicologia, lingüística, pedagogia etc. - têm procurado

\footnotetext{
* Uma primeira versão deste trabalho foi apresentada na
} $28^{a}$ Reunião Anual da Associação Nacional de Pós-Graduação e Pesquisa em Educação (ANPEd). A pesquisa do qual se origina foi financiada pelo Conselho Nacional de Desenvolvimento Científico e Tecnológico (CNPq). redefinir a leitura e a escrita, bem como seu ensino e sua aprendizagem. Apesar das radicais mudanças teóricas produzidas, estudos recentes demonstram a manutenção de práticas didáticas tradicionais nas formas de alfabetizar, tanto crianças como adultos (Oliveira, 2004; Moura, 2001).

Concordando com Chartier (2000), concebemos que as mudanças nas práticas de ensino podem ser de dois tipos. Por um lado, temos aquelas relativas às definições dos "conteúdos" por ensinar, que constituem mudanças de natureza didática. Por outro, temos as mudanças relativas à organização do trabalho pedagógico (modalidades de organização dos alunos na sala de aula, emprego do tempo, formas de avaliação etc.), que se caracterizam como mudanças de natureza pedagógica.

Com base nessas duas categorias, buscamos na presente investigação analisar como as práticas de ensino da leitura e da escrita se concretizam atualmente na etapa de alfabetização inicial, tomando como eixo de investigação a "fabricação" do cotidiano escolar por professoras alfabetizadoras. Priorizamos a análise das formas de ensino da notação alfabética naquela 
etapa de ensino por ser o momento no qual se exige da escola a inserção dos alunos na cultura escrita e a autonomia na leitura e produção de textos.

Apoiamo-nos em dois modelos distintos, que analisam a dinâmica da construção/produção dos saberes escolares: o modelo da transposição didática e aquele que enfoca a construção dos saberes da ação. O primeiro, que enfoca os saberes por ensinar (e o modo como tais saberes diferem dos saberes científicos e daqueles efetivamente ensinados nas escolas), permitiu-nos analisar as mudanças didáticas ligadas ao ensino da leitura e da escrita na alfabetização inicial para verificar como tais proposições têm guiado as práticas dos professores. O segundo modelo, que busca explicar as práticas profissionais e os mecanismos que as caracterizam, permitiu que compreendêssemos melhor a natureza das mudanças observadas nas práticas de ensino dos docentes.

\section{Transposição didática e alfabetização}

Os teóricos da transposição didática propõem uma distinção entre o saber sábio, o saber por ensinar e o saber ensinado (Verret, 1975; Chevallard, 1985). O saber sábio (savoir savant, em francês) corresponderia ao conhecimento científico produzido pelos especialistas de uma disciplina em determinado contexto histórico-social. Tal saber sofre um processo de transposição didática quando muda de seu ambiente original para o espaço institucional de ensino. Transforma-se, então, em saber a ser ensinado, como o que aparece nas propostas curriculares e que se pode materializar em manuais didáticos. Contudo, é evidente que o saber efetivamente ensinado pode corresponder ou não àquele que, em instâncias externas à escola (ministérios, editoras), foi prescrito como o saber por ensinar. Segundo esse enfoque, as mudanças nas práticas dos docentes estariam vinculadas ao processo de transposição didática, no qual se prescrevem novas definições do saber por ensinar.

Se consideramos as mudanças implicadas nos dois primeiros elementos da cadeia de transposição didática (o savoir savant e os textos do saber), vemos que, na área de alfabetização, no Brasil, encontramos nas duas últimas décadas uma verdadeira "revolução" das expectativas elaboradas por aquelas instâncias e propostas.

Vemos que o ensino da leitura e da escrita feito com base no treino das habilidades de "decodificação" e "codificação" do alfabeto tem sido duramente criticado há mais de 20 anos. Tanto nos textos acadêmicos como nos documentos oficiais, investigadores de vários campos passaram a questionar radicalmente o ensino da leitura e da escrita fundamentado no desenvolvimento das habilidades já mencionadas e realizado com o apoio de materiais pedagógicos que priorizavam a memorização de sílabas e palavras ou frases soltas (Marinho, 1998; Mortatti, 2000).

No campo da psicologia, os estudos sobre a psicogênese da língua escrita, desenvolvidos por Emilia Ferreiro e Ana Teberosky (1979), trouxeram contribuição que passou a ocupar lugar especial, inclusive nos currículos nacionais e em materiais pedagógicos produzidos pelo Ministério de Educação para a formação de professores. Como aquela teoria demonstrou que as crianças se apropriam do sistema alfabético de escrita por meio de um processo construtivo, passou-se a defender que aprendam interagindo com os textos escritos. Isto é, o ensino deveria centrar-se em práticas que promovessem a reflexão sobre como funciona o sistema de escrita alfabética (SEA) e nas quais os aprendizes se apropriassem da linguagem convencional dos diferentes gêneros textuais escritos.

Ainda no âmbito das investigações psicolingüísticas, numerosos estudos que examinaram a relação entre habilidades de consciência fonológica e o êxito na alfabetização apontaram a necessidade de promover na escola, desde a etapa de educação infantil, oportunidades de reflexão sobre as palavras como sequiências de segmentos sonoros. Como observa Morais (2004), tal perspectiva tende a conceber a escrita alfabética como um código, cuja aprendizagem continuaria sendo interpretada como resultante de mecanismos de discriminação perceptiva e memorização. Segundo Morais, essa seria a razão que levaria distintos partidários do treino em consciência fonológica a defender a adoção de métodos tradicionais de alfabetização - como o 
método fônico -, sem prescrever que os aprendizes vivam práticas sistemáticas de leitura e produção de textos reais nas etapas iniciais da escolarização.

No meio desse debate, observamos que, na década de 1990, outra perspectiva se consolidou no Brasil: o tratamento do ensino da leitura e da escrita como práticas de letramento. Depois das denúncias formuladas na década anterior, sobre a necessidade de a escola proporcionar aos aprendizes um domínio dos "usos e funções sociais" da leitura e da escrita (Morais \& Albuquerque, 2004), ampliaram-se as críticas ao fato de, na instituição escolar, as práticas com a língua escrita serem tão diferentes daquelas que ocorrem em seu exterior. Com a difusão em nosso país das teorias construtivistas e sociointeracionistas de ensino/aprendizagem de língua nos âmbitos acadêmico e oficial, tornaram-se hegemônicas as propostas que concebem a língua como enunciação, como discurso - e não só como comunicação (Mortatti, 2000; Soares, 1998). Isso implica incluir no tratamento didático as relações da língua com aqueles que a utilizam, com o contexto no qual é utilizada, com as condições sociais e históricas de sua produção e recepção.

Como consequiência, duas questões de natureza didática aparecem nos textos acadêmicos e curriculares sobre alfabetização e sobre ensino de língua que visam a orientar a ação docente: a importância de considerar a alfabetização um processo de apropriação (reconstrução, do ponto de vista cognitivo) do SEA e a necessidade de considerá-la também como prática de letramento ou imersão na cultura escrita.

Além dos efeitos já mencionados nos documentos curriculares e em materiais voltados à formação docente, verificou-se a influência de algumas dessas contribuições teóricas na produção de manuais escolares de alfabetização. Morais e Albuquerque (2005) examinaram as mudanças observáveis nos novos livros de alfabetização, substitutos das cartilhas. As análises realizadas demonstraram que vários livros recomendados pelo Ministério da Educação ${ }^{1}$ não propunham

${ }^{1}$ Recordemos que, desde 1998, os livros didáticos adquiridos pelo governo brasileiro para os estudantes das escolas públicas são um ensino sistemático da escrita alfabética. Tendiam, sim, a apresentar um leque muito variado de textos, de gêneros bastante distintos, o que indica uma evidente preocupação de letrar ou aproximar os novos aprendizes da cultura escrita. Embora a maioria dos autores dos novos manuais declarasse adotar concepções construtivistas e socioconstrutivistas de língua e aprendizagem, suas obras didáticas tendiam a não promover a produção de escritas espontâneas nem o diagnóstico, pelos professores, do nível alcançado pelos alunos no que concerne à compreensão da notação alfabética. Além disso, quase nunca propunham tarefas ou atividades que promovessem a reflexão metafonológica das crianças, o que sugere baixa influência dos estudos sobre consciência fonológica na recente didatização da alfabetização no Brasil.

Se nos últimos séculos os manuais didáticos constituíram uma importante ferramenta para os professores, as mudanças agora mencionadas parecem não satisfazer os que ensinam com aqueles manuais. Examinando as práticas e concepções de docentes de três cidades em Pernambuco, Araújo (2004) constatou que os professores que empregavam os novos livros de alfabetização reconheciam a qualidade do repertório textual oferecido, mas queixavam-se explicitamente da ausência, nos livros, de atividades para ensinar aos alunos a notação alfabética. Diziam que de nada servia letrar os alunos sem que aprendessem o bế-á-bá para que pudessem ler de forma efetiva e autônoma.

Nesse contexto, buscamos nesta investigação examinar a dimensão didática das práticas adotadas pelos professores para alfabetizar seus alunos: que conteúdos e atividades costumavam priorizar para ensinar a notação alfabética, que práticas de leitura e produção de textos escritos costumavam desenvolver e como vinculavam, em seu ensino, esses dois domínios

avaliados por comissões de especialistas das distintas disciplinas do currículo pelo Programa Nacional de Avaliação do Livro Didático (PNLD). Os professores e demais profissionais das redes públicas de ensino que escolhem os manuais que utilizarão só podem selecionar a partir da lista de livros recomendados por aquelas comissões. 
de conhecimento (notação alfabética e apropriação da linguagem dos gêneros escritos).

\section{Mudanças didáticas e pedagógicas nas práticas de alfabetização: construção/fabricação de saberes no cotidiano da sala de aula}

O termo cotidiano é ambíguo e freqüentemente empregado para designar as rotinas ou banalidades. É concebido em muitas ocasiões como algo que "está nos objetos" ou, em outros momentos, como algo que "está fora dos eventos importantes". Ao falar sobre a fabricação do cotidiano, buscamos, de modo diferente, demonstrar que a maneira como os atores intervêm na escola é inventiva e produtiva, porque não faz sentido tratar de forma idêntica as situações encontradas, porque valoram distintamente umas e outras situações. As interpretações dos atores são o que dá significados e sentidos diferentes às situações diárias, conforme os eventos e os contextos de cada realidade.

No espaço escolar, a convivência com distintas formas de cultura favorece uma construção contínua de acordos e "fabricações" que possibilitam a dinâmica de sua existência. Como afirma Certeau (1974), "a escola [...] talvez seja um dos locais onde se põe em ação uma articulação entre o saber técnico e a relação social e onde se efetua, graças a uma prática coletiva, o reajuste necessário entre modelos culturais contraditórios".

Dentro das salas de aula das escolas, não se identifica a existência de um discurso totalmente construído sobre o que se deve ou não fazer, sobre o que está permitido ou sobre o que pode ser uma sala de alfabetização. No entanto, identificamos, por meio de muitas ações e palavras, múltiplos elementos que convergem bastante para que se possa dizer que existe uma prática sobre regras (escritas e orais) da prática pedagógica do professor alfabetizador. Essa posição não cobre a totalidade das posições individuais, já que cada uma guarda certa margem de distância possível com respeito ao que é percebido como "posição da escola”. Tal posição tampouco está exaustivamente traduzida em um discurso coerente e fixo.
É necessário distinguir os discursos individuais e coletivos construídos pelas pessoas da escola dos discursos elaborados sobre ela a partir de uma racionalidade técnica, política e científica (academia/ ministérios e secretarias/organizações sindicais). Os primeiros (os discursos construídos pelos atores que atuam na escola) não se apresentam nas práticas das realidades escolares do mesmo modo como foram "estrategicamente" elaborados, mas de um modo "taticamente" fabricado. Segundo Anne-Marie Chartier (2002, p. 5),

\begin{abstract}
[...] a racionalidade está do lado dos discursos construídos que ordenam operações de modo coerente, das premissas às conclusões, das causas aos efeitos, dos meios aos fins. Todos os discursos teóricos das ciências humanas fascinam ou seduzem porque transformam o mundo em livro, porque põem em lugar da confusão caótica dos acontecimentos e fenômenos a maravilhosa legibilidade construída, abstrata, imposta ou desejada.
\end{abstract}

Entretanto, na realidade prática, o que ocorre não é exatamente o que está escrito. As práticas cotidianas revelam que os discursos são transformados conforme os contextos e as conjunturas das diferentes culturas.

De fato, se concordamos com Certeau (1990) e adotamos sua oposição entre estratégias e táticas, identificamos, por um lado, o que provém das produções estratégicas duráveis, aquelas que são explícitas nas instituições, nos regulamentos, nos projetos etc. Por outro lado, vislumbramos o que provém das táticas, aquilo que se joga no terreno do outro, que são "apropriações", "interpretações", mudanças, reparos e readaptações. Em tais apropriações singulares, os sujeitos reagem a seu modo ante as pressões de cada situação (o "aqui e agora" de cada escola, a partir de suas características locais e de seus eventos) e as interferências externas das diferentes instituições que fixam as normas e os objetivos a curto e longo prazo.

Nesse sentido, a perceptiva teórica de Michel de Certeau e o enfoque da construção dos saberes na ação orientaram nossa investigação sobre as práticas 
cotidianas dos professores de alfabetização. Como Certeau, consideramos que essas práticas cotidianas são produzidas/fabricadas pelos próprios atores. Elas referem-se a uma "produção cultural", embora não sejam propriamente "obras" (no sentido de obras de arte ou instituições duráveis).

Nessa perspectiva, procuramos compreender como as fabricações de práticas alfabetizadoras se davam no cotidiano de escolas públicas de nosso país em um contexto de redefinição dos saberes a ensinar naquela etapa da escolarização. Como já dissemos, interessavanos particularmente examinar as soluções didáticas fabricadas para ensinar a notação alfabética.

\section{Metodologia}

Nesta pesquisa, em função da própria natureza do objeto e da escolha teórica, privilegiamos a perspectiva etnográfica da pesquisa qualitativa. Concordando com Denzin e Lincoln (1994), concebemos que ela consiste na descrição e interpretação de grupos humanos com base no contato intenso e multifacetado em que se valorizam, na ação, os elementos simbólicos das relações sociais.

A pesquisa foi desenvolvida com um grupo de nove professoras de alfabetização ( $\left(1^{\circ}\right.$ ano do primeiro ciclo) da Secretaria de Educação da cidade do Recife no ano de 2004. O quadro 1 apresenta alguns dados sobre as professoras.

Para registrar como as professoras estavam transpondo as mudanças didáticas relacionadas à alfabetização para suas práticas de ensino e comofabricavam suas práticas pedagógicas cotidianas, utilizamos a observação participante como procedimento metodológico.

As observações de aula foram realizadas no período de junho a dezembro de 2004, totalizando dez observações em cada sala de aula. Analisamos também o material usado pelas docentes para o ensino da leitura e da escrita, principalmente os livros didáticos utilizados $^{2}$ e os cadernos dos alunos.

\footnotetext{
${ }^{2}$ O livro didático de alfabetização adotado por toda a rede
} municipal de ensino da cidade do Recife em 2004 foi Português:
Quadro 1: Apresentação do perfil das professoras

\begin{tabular}{|c|c|c|c|c|c|}
\hline & Idade & Formação & Pós- & \begin{tabular}{|c} 
Tempo de \\
magistério \\
(anos)
\end{tabular} & $\begin{array}{c}\text { Turnos } \\
\text { de } \\
\text { trabalho }\end{array}$ \\
\hline Claudecy & 38 & Pedagogia & & 13 & 2 \\
\hline Cláudia & 32 & Pedagogia & Sim & 12 & 2 \\
\hline Daniele & 28 & Pedagogia & & 7 & 2 \\
\hline Eleuses & 63 & $\begin{array}{l}\text { Pedagogia } \\
\text { (cursando) }\end{array}$ & & 21 & 1 \\
\hline Leônia & 41 & Pedagogia & Sim & 13 & 2 \\
\hline $\begin{array}{l}\text { Ana } \\
\text { Luzia }\end{array}$ & 50 & Pedagogia & & 15 & 2 \\
\hline Mônica & & Pedagogia & & 12 & 1 \\
\hline Patrícia & 28 & Pedagogia & & 01 & 2 \\
\hline Solange & 40 & Pedagogia & Sim & 21 & 2 \\
\hline
\end{tabular}

Durante o período das observações, realizamos mensalmente um encontro com as professoras, no qual desenvolvíamos um trabalho com a técnica de grupo focal. A cada encontro discutíamos temas relativos à alfabetização, tanto do ponto de vista teórico quanto das práticas de ensino das docentes. As temáticas trabalhadas foram: memórias e concepções de alfabetização, atividades de rotina da sala de alfabetização, uso do livro didático, importância do trabalho com textos para alfabetizar e promoção de habilidades de reflexão fonológica.

\section{O que faziam as professoras? Análise das observações das práticas}

Para cada dia de aula observado, elaboramos um protocolo de observação e, a partir da análise do conjunto de protocolos, categorizamos as atividades das professoras nos seguintes eixos: atividades de rotina, atividades de apropriação do SEA, atividades de leitura e produção de textos e atividades de desenho. Em cada eixo, elencamos um conjunto de subcategorias relacionadas às atividades desenvolvidas.

No que se refere às atividades de apropriação do SEA, foco deste trabalho, elas foram categorizadas nas

uma proposta para o letramento, de Gladys Rocha, publicado pela editora Moderna. 
seguintes subcategorias, baseadas no estudo prévio de Morais e Albuquerque (2005):

- leitura de letras, sílabas, palavras ou frases com ou sem auxílio do professor;

- escrita de letras, sílabas, palavras e frases com e sem auxílio do professor;

- cópia de letras, sílabas, palavras e frases;

- contagem de letras em sílabas, de letras e sílabas em palavras e de palavras em frases;

- partição de palavras em sílabas e letras ou de frases em palavras;

- identificação de letras e sílabas em palavras;

- identificação, exploração e produção de rimas e aliterações;

- comparação de: sílabas e palavras quanto ao número de letras; palavras quanto ao número de sílabas, palavras quanto à presença de letras iguais/diferentes;

- formação de palavras a partir de letras ou sílabas dadas;

- exploração de diferentes tipos de letra, da ordem alfabética, da segmentação das palavras e das relações som/grafia.

Após a análise das dez observações realizadas na sala de cada professora com base na categorização descrita, classificamos suas práticas de alfabetização, no que se refere ao trabalho com o sistema de escrita alfabética, em dois tipos, descritos a seguir.

\section{Prática sistemática de alfabetização}

Essa modalidade engloba as práticas que apresentaram trabalho sistemático de apropriação do sistema de escrita alfabética, pois contemplaram em todos os dias observados algumas das atividades relacionadas a esse eixo. As professoras cujas práticas foram classificadas nessa categoria foram: Cláudia, Patrícia, Mônica, Solange e Eleuses. As quatro primeiras apresentaram práticas parecidas, pois desenvolviam diariamente atividades variadas que envolviam reflexão sobre os princípios do SEA. Para exemplificar o que estamos chamando de prática sistemática, apoiaremo-nos no trabalho da professora Cláudia.

A Tabela 1 apresenta as atividades de apropriação do SEA desenvolvidas por essa professora no decorrer das dez observações. Podemos verificar que, nos dias de aula observados, foram realizadas atividades diferenciadas de apropriação do SEA. Escrita e leitura de palavras foram as mais freqüentes. As atividades de contagem (de letras, sílabas e palavras) foram realizadas, no conjunto, em sete dias. Com exceção do sétimo e oitavo dias, todos os outros envolveram, além da leitura e escrita de palavras, pelo menos um dos seguintes tipos de atividade: contagem, partição, identificação, comparação, formação e exploração de diferentes unidades lingüísticas, o que significa que sistematicamente os alunos eram solicitados a realizar atividades que levavam à reflexão sobre os princípios do SEA.

Tais atividades foram exploradas pela professora Cláudia sobretudo com tarefas elaboradas por ela e mimeografadas para os alunos, o que indicava busca de suplementação do que apontava como lacunas no livro didático da turma.

É importante frisar que as atividades eram realizadas primeiramente junto com a professora no quadro; depois as crianças respondiam. Provavelmente tal prática pode justificar o fato de a categoria escrita de palavra como souber ter aparecido apenas uma vez nos nossos registros, já que as crianças sempre escreviam com auxílio do professor, como pode ser evidenciado na Tabela 1 . Tal fato se diferencia da leitura de palavras, uma vez que, então, os alunos leram mais vezes sozinhos.

Observamos que muitas categorias de apropriação do SEA eram trabalhadas. Entretanto, julgamos que algumas mereciam sistematização maior, como: contagem de letras de palavras, partição escrita de palavras em letras, partição escrita de palavras em sílabas e comparação de palavras quanto à presença de sílabas iguais/diferentes, tendo em vista o papel que exercem na apreensão de propriedades do SEA.

Os encadeamentos dessas atividades de apropriação do SEA na prática da professora Cláudia puderam 
Tabela 1. Descrição das práticas de ensino do sistema de escrita alfabética desenvolvidas pela professora Cláudia

\begin{tabular}{|c|c|c|c|c|c|c|c|c|c|c|}
\hline Categorias/Observações & 1 & 2 & 3 & 4 & 5 & 6 & 78 & 89 & \begin{tabular}{l|l}
9 & 1 \\
\end{tabular} & 10 \\
\hline \multicolumn{11}{|l|}{ Apropriação do SEA } \\
\hline Leitura de sílabas & & & & & & & & & & $X$ \\
\hline Leitura de palavras & $x$ & $x$ & $x$ & $\mathrm{X}$ & $x$ & $x$ & & $x \mid \gamma$ & $x$ & \\
\hline Escrita de palavra & & $x$ & & $\mathrm{X}$ & & & $x$ & & & $X$ \\
\hline $\begin{array}{l}\text { Escrita de palavras a partir de } \\
\text { letra/sílaba dada }\end{array}$ & $x$ & $x$ & $x$ & $X$ & & $x$ & & & $x \mid \gamma$ & $X$ \\
\hline $\begin{array}{l}\text { Escrita de palavra com auxílio } \\
\text { do professor }\end{array}$ & $x$ & $x$ & $x$ & $\mathrm{X}$ & $x$ & $x \mid \gamma$ & $x \mid>$ & $x \mid \gamma$ & $x \mid \gamma$ & $X$ \\
\hline Cópia de sílaba & & & & & & $\mathrm{X}$ & & & & \\
\hline Cópia de palavra & $X$ & & $\mathrm{X}$ & $\mathrm{X}$ & & $\mathrm{X}$ & & $\mathrm{X}$ & & \\
\hline Cópia de frase & & & & $\mathrm{X}$ & & & & $X$ & & $x$ \\
\hline $\begin{array}{l}\text { Contagem de letras de } \\
\text { palavras }\end{array}$ & & & & & & $x$ & & & & \\
\hline $\begin{array}{l}\text { Contagem de sílabas de } \\
\text { palavras }\end{array}$ & $x$ & & $x$ & & & $x$ & & & $x \mid \gamma$ & $X$ \\
\hline Contagem de palavras & & & $\mathrm{x}$ & $\mathrm{X}$ & $X$ & & & & & \\
\hline $\begin{array}{l}\text { Partição oral de palavras em } \\
\text { sílabas }\end{array}$ & $x$ & & $x$ & & & & & & & $x$ \\
\hline $\begin{array}{l}\text { Partição escrita de palavra em } \\
\text { letras }\end{array}$ & $x$ & & & & & & & & & \\
\hline $\begin{array}{l}\text { Partição escrita de palavra em } \\
\text { sílabas }\end{array}$ & & & & & $X$ & & & & & \\
\hline Identificação de letras & & & $x$ & & & & & & & \\
\hline $\begin{array}{l}\text { Identificação de sílabas com } \\
\text { correspondência escrita }\end{array}$ & & & $x$ & & & & & & $x$ & \\
\hline $\begin{array}{l}\text { Identificação de sílabas sem } \\
\text { correspondência escrita }\end{array}$ & & & $x$ & & & & & & & \\
\hline $\begin{array}{l}\text { Identificação de palavras com } \\
\text { outros critérios }\end{array}$ & & & & & $X$ & & & & $x$ & \\
\hline $\begin{array}{l}\text { Identificação de palavras que } \\
\text { possuam a sílaba X }\end{array}$ & & & & & $X$ & & & & & \\
\hline $\begin{array}{l}\text { Identificação de } \\
\text { rima/aliteração com } \\
\text { correspondência escrita }\end{array}$ & & $X$ & $x$ & & & & & & & $X$ \\
\hline $\begin{array}{l}\text { Produção de rima/aliteração } \\
\text { com correspondência escrita }\end{array}$ & & & $x$ & & & & & & & $X$ \\
\hline $\begin{array}{l}\text { Comparação de palavras } \\
\text { quanto ao número de sílabas }\end{array}$ & & & $x$ & & & & & & & $x$ \\
\hline $\begin{array}{l}\text { Comparação de palavras } \\
\text { quanto à presença de silabas } \\
\text { iguais/diferentes }\end{array}$ & & & & & & $x$ & & & & \\
\hline $\begin{array}{l}\text { Formação de palavras com } \\
\text { outros critérios }\end{array}$ & & & & & & & & & $x$ & \\
\hline $\begin{array}{l}\text { Exploração dos diferentes } \\
\text { tipos de letras }\end{array}$ & $x$ & & & $x$ & & & & & & \\
\hline
\end{tabular}

também ser evidenciados ao analisarmos suas aulas. Isso pode ser exemplificado com o que ocorreu no dia da terceira observação. Naquela tarde, a professora Cláudia fez inicialmente a leitura do livro Bebela, $a$ pulguinha sapeca e a partir dele trabalhou as seguintes categorias: partição oral de palavras em sílabas, produção de rima/aliteração com correspondência escrita, leitura de palavras com auxílio do professor, identificação de sílabas em posição inicial sem correspondência escrita, leitura de palavras, comparação de palavras quanto ao número de sílabas, contagem de sílabas de palavras e contagem de palavras. Ao final, os alunos agruparam em duas colunas as palavras que produziram e exploraram (oralmente e por escrito), conforme o número de sílabas que apresentaram e as anotaram em seus cadernos.

Quanto às atividades que envolviam leitura, é importante salientar que a professora costumava ler livros de literatura infantil para a turma após o recreio, organizando os alunos em roda de leitura. Observamos que, em geral, essas eram leituras para deleite. Já a produção de textos foi pouco explorada, ocorrendo duas vezes, sendo uma produção de texto coletivo e outra produção de texto como souber. Essas atividades de produção textual concentraram-se no final do período das observações.

A professora Eleuses desenvolvia uma prática sistemática relacionada à alfabetização, mas vinculada aos métodos tradicionais. Trabalhava diariamente com a memorização de sílabas e cópia de palavras retiradas de diferentes gêneros de textos, como pode ser observado na Tabela 2.

Analisando os dados da tabela, constatamos que a professora priorizou, em suas aulas, a cópia de palavras e frases, atividades que foram registradas em todas as observações. Apesar de não intitular essa atividade como cópia, ela solicitava que os alunos copiassem o que ela havia escrito no quadro; essa prática diária correspondia a mais da metade do tempo total gasto com as atividades de apropriação do SEA. Já a leitura de palavras foi o segundo item com maior freqüência (quatro registros dessa atividade). As categorias escrita de frase, contagem de letras/sílabas 
Tabela 2. Descrição das práticas de ensino do sistema de escrita alfabética desenvolvidas pela professora Eleuses

\begin{tabular}{|c|c|c|c|c|c|c|c|c|}
\hline Categorias/Observações & 1 & 2 & \begin{tabular}{l|l}
3 & 4 \\
\end{tabular} & 45 & 67 & \begin{tabular}{l|l}
7 & 8 \\
\end{tabular} & $8 \quad 9$ & 10 \\
\hline \multicolumn{9}{|l|}{ Apropriação do SEA } \\
\hline Leitura de palavras & & & \begin{tabular}{l|l}
$X$ \\
\end{tabular} & $x \mid x$ & & $\mathrm{X}$ & & \\
\hline Leitura de frases com auxílio & & & & $x$ & & & $x$ & \\
\hline Escrita de letra & & $x$ & & & & & & \\
\hline $\begin{array}{l}\text { Escrita de palavras como } \\
\text { souber }\end{array}$ & $x$ & $x$ & & & & & & \\
\hline Escrita de frase & $x$ & $x$ & & $\mathrm{X}$ & & & & \\
\hline Cópia de palavra & $\mathrm{x}$ & $\mathrm{X}$ & \begin{tabular}{l|l}
$X$ & $x$ \\
\end{tabular} & $\mathrm{X} x$ & $x \mid \gamma$ & \begin{tabular}{l|l}
$X$ & $X$ \\
\end{tabular} & \begin{tabular}{l|l|}
$x$ & $x$ \\
\end{tabular} & $\mathrm{X}$ \\
\hline Cópia de frase & $\mathrm{x}$ & $\mathrm{X}$ & \begin{tabular}{l|l}
$X$ & $X$ \\
\end{tabular} & \begin{tabular}{|l|l|}
$x$ \\
\end{tabular} & $x \mid \gamma$ & \begin{tabular}{l|l}
$X$ & $X$ \\
\end{tabular} & \begin{tabular}{l|l|}
$x$ & $x$ \\
\end{tabular} & $\mathrm{X}$ \\
\hline $\begin{array}{l}\text { Contagem de letras de } \\
\text { palavras }\end{array}$ & $x$ & & $x \mid x$ & $x$ & & & & \\
\hline $\begin{array}{l}\text { Contagem de sílabas de } \\
\text { palavras }\end{array}$ & $x$ & & $x \mid X$ & $x$ & & & & \\
\hline Contagem de palavras & & $\mathrm{X}$ & \begin{tabular}{l|l}
$x$ & $x$ \\
\end{tabular} & $\mathrm{x}$ & & & & \\
\hline $\begin{array}{l}\text { Partição oral de palavras em } \\
\text { sílabas }\end{array}$ & & & $x \mid x$ & $x$ & & $x$ & & \\
\hline $\begin{array}{l}\text { Partição escrita de palavra em } \\
\text { sílabas }\end{array}$ & $x$ & & & $x$ & & $x$ & & \\
\hline $\begin{array}{l}\text { Identificação de rima/ } \\
\text { aliteração c/correspondência } \\
\text { escrita }\end{array}$ & & & & & & $x$ & & \\
\hline $\begin{array}{l}\text { Comparação de palavras } \\
\text { quanto ao número de letras }\end{array}$ & $x$ & & & & & & & \\
\hline $\begin{array}{l}\text { Comparação de palavras } \\
\text { quanto ao número de sílabas }\end{array}$ & $x$ & & & & & & & \\
\hline $\begin{array}{l}\text { Formação de palavras a partir } \\
\text { de letras dadas }\end{array}$ & & & $X$ & & & & $X$ & \\
\hline $\begin{array}{l}\text { Formação de palavras a partir } \\
\text { de sílabas dadas }\end{array}$ & $x$ & & & & & & & \\
\hline $\begin{array}{l}\text { Exploração da relação som/ } \\
\text { grafia }\end{array}$ & $x$ & & & & & & $x$ & \\
\hline
\end{tabular}

e palavras, partição oral de palavras em sílabas, partição escrita de palavra em sílabas apareceram em três das aulas observadas.

Um ponto curioso foi o fato de a professora, na primeira observação, ter praticado um número considerável de atividades encadeadas: partição escrita de palavra em letras, comparação de palavras quanto ao número de letras, comparação de palavras quanto ao número de sílabas, formação de palavras a partir de sílabas dadas. Esse encadeamento, porém, não foi repetido em outras aulas.
Um fato que chamou a atenção foi quando a professora, no $7^{\circ}$ registro de aula, utilizou o recurso da rima nas atividades com seus alunos. Podemos caracterizar o acontecimento como uma "mudança", já que a docente declarou, antes dos encontros mensais de grupo focal que vivenciou conosco, que não empregava esse dispositivo para a alfabetização.

Registramos o trabalho de leitura de textos pela professora em cinco observações e interpretação $e$ reconstrução em quatro aulas. A produção de texto coletivo foi identificada em uma aula. Os gêneros de texto que a professora utilizou foram: histórias, contos, panfletos e poemas, o que demonstra preocupação com a diversidade textual. No entanto, ela utilizava os textos apenas para, a partir deles, ensinar letras e sílabas.

Isso ficou evidente quando analisamos a seqüência desenvolvida por ela a cada aula. No caso da $5^{\mathrm{a}}$ aula observada, por exemplo, a professora afixou no quadro dois cartazes; o primeiro era uma fábula (Os viajantes e o urso); o outro tratava de como se deve tratar os amigos. Leu os dois cartazes em voz alta e em seguida perguntou aos alunos quem eram os personagens da história e o que eles faziam (no caso do primeiro cartaz) e falou sobre a moral da história (referente ao segundo cartaz). Depois escreveu algumas palavras do texto no quadro e realizou uma leitura coletiva delas. Separou, então, a primeira palavra em sílabas, contou o número de letras e sílabas e solicitou que os alunos copiassem e fizessem o mesmo, dessa vez de forma individual, com as demais palavras. Após meia hora, a professora realizou a atividade no quadro junto com os alunos.

Podemos então dizer que ela trabalhava um "método cartilhado sem cartilha", ou seja, não ensinava BA-BE-BI-BO-BU, mas utilizava a apresentação de textos para levar os alunos a memorizar letras ou sílabas soltas. Isso parece ser uma recriação da professora a partir das novas orientações sobre alfabetização e letramento, já que, para alfabetizar na perspectiva do letramento, se orienta a trabalhar com diversos gêneros textuais. Assim, a professora parecia desenvolver uma prática tradicional com uma nova roupagem. 
Prática assistemática de alfabetização

Essa modalidade compreende as práticas que priorizavam as atividades de leitura e produção de textos e que, no conjunto das dez observações, contemplaram muito pouco as atividades relacionadas à apropriação do SEA. As professoras cujas práticas foram classificadas nessa categoria foram Ana Luzia, Claudecy, Leônia e Daniele.

A Tabela 3 apresenta as atividades de apropriação do SEA desenvolvidas pela professora Ana Luzia no decorrer de nove observações. A partir da tabela, percebemos que as atividades que envolviam a apropriação do SEA não foram exploradas de forma sistemática. As crianças foram pouco convidadas a escrever sozinhas. Elas passavam a maior parte do tempo copiando a tarefa de classe, de casa e desenhando.

As tarefas de classe e casa tinham basicamente os seguintes exercícios: desenho relativo a uma leitura, ditado mudo (escrita do nome de figuras) e completar frases com palavras. Os dois últimos são exemplos da categoria escrita de palavra. Isso demonstra uma preocupação maior da professora com a palavra, em detrimento da reflexão sobre as unidades que a compõem.

Percebemos que, apesar de o SEA na maioria das observações não ter sido enfocado pela professora, havia maior número de atividades dessa natureza na quinta e na sexta observação. Nessas aulas apareceram as categorias que trabalham os processos cognitivos de contagem, partição, identificação e formação. A professora, porém, só explorou essas categorias na modalidade oral, coletivamente, e não fez nenhuma comparação de palavras quanto ao número de sílabas. Também não houve trabalho sistemático envolvendo as atividades de consciência fonológica, em que os alunos refletiriam sobre as partes e os sons que compõem a palavra.

$\mathrm{O}$ ditado foi uma atividade que a docente realizou algumas vezes. Essa era uma das poucas tarefas em que as crianças eram solicitadas a escrever (em lugar de copiar). Nesse momento, a professora explorava alguns processos cognitivos, como contagem, partição, comparação, identificação e formação. Entretanto, isso
Tabela 3. Descrição das práticas de ensino do sistema de escrita alfabética desenvolvidas pela professora Ana Luzia

\begin{tabular}{|c|c|c|c|c|c|c|c|c|}
\hline Categoria/Observação & 1 & 2 & 3 & 4 & 5 & 6 & 7 & 9 \\
\hline \multicolumn{9}{|l|}{ Apropriação do SEA } \\
\hline $\begin{array}{l}\text { Leitura de letras/alfabeto com } \\
\text { auxílio }\end{array}$ & & & & & & $\mathrm{X}$ & & \\
\hline Leitura de sílabas & & & $X$ & & & & & \\
\hline Leitura de palavras & & & & & $x$ & & $x$ & \\
\hline Escrita de palavra & & & & & $x$ & & & \\
\hline $\begin{array}{l}\text { Escrita de palavras a partir de } \\
\text { letra/sílaba dada }\end{array}$ & & & $x$ & & & & & \\
\hline Escrita de palavra como souber & & & & $\mathrm{X}$ & & & & \\
\hline Escrita de frase & & $\mathrm{X}$ & & & & & & \\
\hline Cópia de palavra & & $\mathrm{X}$ & $X$ & $\mathrm{x}$ & $x$ & \begin{tabular}{l|l}
$x$ & $y$ \\
\end{tabular} & $\mathrm{x}$ & $X$ \\
\hline Contagem de letras de palavras & & & $X$ & & $x$ & $x$ & & \\
\hline $\begin{array}{l}\text { Contagem de sílabas de } \\
\text { palavras }\end{array}$ & & & $x$ & & & $x$ & $X$ & \\
\hline $\begin{array}{l}\text { Partição oral de palavras em } \\
\text { sílabas }\end{array}$ & & & $x$ & $x$ & & $x$ & & $x$ \\
\hline $\begin{array}{l}\text { Partição escrita de palavra em } \\
\text { sílabas }\end{array}$ & & & & & & & $X$ & \\
\hline $\begin{array}{l}\text { Diferenciação de letras/palavras/ } \\
\text { números/ outros }\end{array}$ & & & & & $x$ & & & \\
\hline $\begin{array}{l}\text { Identificação de letras em } \\
\text { posição X }\end{array}$ & & & & & $x$ & & & \\
\hline $\begin{array}{l}\text { Identificação de letras (iguais) } \\
\text { em palavras }\end{array}$ & & & & & $x$ & & & \\
\hline $\begin{array}{l}\text { Identificação de sílabas em } \\
\text { posição X sem correspondência } \\
\text { escrita }\end{array}$ & & & & & & $\mathrm{X}$ & & \\
\hline $\begin{array}{l}\text { Identificação de palavras com } \\
\text { outros critérios }\end{array}$ & & & $x$ & & & & & \\
\hline $\begin{array}{l}\text { Identificação de palavras que } \\
\text { possuam a letra X }\end{array}$ & & & $x$ & & $x$ & & & \\
\hline $\begin{array}{l}\text { Identificação de rima/aliteração } \\
\text { sem correspondência escrita }\end{array}$ & & & $x$ & & & & & \\
\hline $\begin{array}{l}\text { Produção de rima/aliteração } \\
\text { sem correspondência escrita }\end{array}$ & & & & $x$ & & & & \\
\hline $\begin{array}{l}\text { Comparação de palavras quanto } \\
\text { ao número de letras }\end{array}$ & & & & & & $x$ & & \\
\hline $\begin{array}{l}\text { Comparação de palavras quanto } \\
\text { ao número de sílabas }\end{array}$ & & & & & & & $x$ & \\
\hline $\begin{array}{l}\text { Formação de palavras a partir } \\
\text { de letras dadas }\end{array}$ & & & & & & & & \\
\hline $\begin{array}{l}\text { Formação de palavras com o } \\
\text { uso do alfabeto móvel } \\
\end{array}$ & & & $x$ & & & & & \\
\hline Exploração da ordem alfabética & & & $x$ & & & & & \\
\hline
\end{tabular}


era feito oral e coletivamente. No momento em que ditava as palavras, ela explorava um pouco a escrita delas, mas na hora de corrigir o ditado não levava os alunos a refletir sobre a escrita delas, apenas passava de banca em banca e escrevia as formas corretas, ao lado das palavras previamente escritas pelo aluno.

No que se refere à leitura, a professora leu todos os dias para as crianças. A leitura sempre acontecia no início das aulas e estava relacionada à temática que seria trabalhada. Para isso, ela trazia cartazes, textos produzidos pelas crianças em aulas anteriores, fragmentos de textos e livros de história.

Os textos sempre eram lidos por ela. Quando solicitava que os alunos a ajudassem no momento da leitura, poucos o faziam. Percebemos, assim, que o ensino de leitura predominou na prática da professora. Mas em nenhum momento os alunos realizaram uma leitura coletiva ou silenciosa.

As atividades de produção coletiva de textos não tinham destinatário real ou finalidade específica. Os gêneros produzidos durante as aulas foram: recado, bilhete, diálogo e lista, ocorrendo este último com maior incidência. A composição dos textos, na maioria das vezes, era feita pela professora, ou seja, durante a atividade os alunos poucas vezes interagiam com ela na construção do texto em si.

Constatamos, enfim, que a professora não ensinou o SEA de forma sistemática. Ela priorizava, em sua prática, a leitura de textos, a produção de texto coletivo, o desenho relativo a leitura e o desenho sem finalidade específica, em detrimento das atividades relacionadas à apropriação do sistema alfabético.

Nas observações realizadas, o livro didático só foi utilizado uma vez: para ilustrar a fala da professora, na hora de contar uma história.

\section{Algumas considerações finais}

Inicialmente, gostaríamos de enfatizar uma relação entre os tipos de práticas de alfabetização feitos pelas professoras e alguns aspectos de suas experiências de formação inicial e trajetória profissional. Em relação às docentes cujas práticas foram classificadas como sistemáticas e cujas didáticas se distanciavam de métodos tradicionais de alfabetização, três lecionavam em uma mesma escola (Cláudia, Patrícia e Leônia); as duas primeiras trabalhavam juntas em uma outra escola da rede privada no turno da manhã e vivenciavam, naquela instituição, um trabalho de formação continuada na área de alfabetização. Elas disseram que "traziam muitas atividades daquela escola para serem realizadas com os alunos da rede pública". Ainda naquele primeiro grupo, a professora Solange tinha vivenciado um trabalho de formação na área de alfabetização na época do Ciclo de Alfabetização da rede municipal de ensino do Recife (de 1986 a 1988), no qual se discutia, em encontros quinzenais (durante todo o ano letivo), a importância de desenvolver atividades de leitura e produção de textos concomitantemente com atividades de reflexão fonológica e de exploração das propriedades do sistema de escrita alfabética. Percebemos que, quase duas décadas depois, aqueles eixos ou prioridades guiavam seu ensino.

Consideramos, também, que a análise das práticas de alfabetização apresentada aqui permitiu ver a influência do imaginário e de certo discurso pedagógico hoje dominante no campo da alfabetização. $\mathrm{O}$ fato de que menos da metade das professoras que acompanhamos investia no ensino sistemático da notação alfabética demonstra a urgência da reflexão sobre os efeitos do discurso que critica a redução da alfabetização a estratégias de "codificação-decodificação", que parece priorizar a imersão na cultura escrita (o letramento), no que seria supostamente uma "ação reparadora" para com os alunos de meios sociais desfavorecidos logo nas etapas iniciais da escolarização. Como enfatiza Soares (2003), estaríamos deixando de tratar as especificidades da alfabetização como aprendizado de um objeto (escrita alfabética) que requer metodologias de ensino específicas.

As docentes que acompanhamos revelavam ter conhecimento razoável das propostas didáticas que privilegiam a realização de práticas de leitura e produção de textos desde o início da alfabetização. Mesmo as professoras cujas práticas foram classificadas como assistemáticas priorizavam atividades de leitura de textos 
e se preocupavam com a diversidade de gêneros textuais empregados. A partir dessa perspectiva, concebiam estar desenvolvendo um ensino diferente e inovador. No entanto, não asseguravam um ensino voltado ao domínio da notação alfabética, para que seus alunos pudessem tornar-se em curto prazo leitores minimamente autônomos na tradução da notação escrita.

O depoimento da professora Ana Luzia, em um dos encontros finais do grupo focal, é revelador dessa questão. Ela falou:

Agora eu sei por que meus alunos não estão alfabetizados. Eu trabalho muito com leitura e produção de textos, mando desenhar, mas não realizo essas atividades de reflexão com as palavras. Agora vou fazer diferente.

Ainda na perspectiva do discurso do letramento, cabe mencionar a distância entre as expectativas dos acadêmicos sobre como desenvolver as situações de tratamento dos textos e o que pudemos verificar nas aulas. A explicitação de finalidades para as atividades (de leitura ou produção de textos), a definição de destinatários ou a discussão sobre características da língua escrita adequadas a cada gênero praticado nunca ou quase nunca foram objeto de reflexão nas situações observadas nas salas de aula. Nas situações de produção de textos coletivos, as crianças tendiam a participar pouco na definição da forma composicional do produto que, no final da atividade, tinham que copiar em seus cadernos.

Outro dado que requer menção especial foi a não-submissão das professoras à proposta do livro didático que, sem que fossem consultadas, tinha chegado a todas as salas de aula de alfabetização da rede de ensino em que atuavam. Em oposição a uma visão reducionista que pressupõe que os docentes "seguem o que se propõe nos livros didáticos”, as práticas das professoras alfabetizadoras pareciam apoiar-se em determinadas maneiras de entender o processo de alfabetização que por sua vez estariam ligadas a suas histórias enquanto sujeitos que foram alfabetizados, que vivenciaram (e vivenciam) um processo de formação e que se tornaram profissionais. Toda essa trajetória vivida pelas professoras parecia refletir na fabricação de suas práticas em sala de aula ante os modelos cientificamente elaborados e transformados em prescrições por instâncias externas à escola. Noutras palavras, as mudanças das práticas ante as novas descobertas sobre alfabetização não se apresentariam da mesma forma que foram pensadas ou escritas pelos especialistas, o que indica certa limitação da teoria da transposição didática na compreensão dos processos que geram os saberes efetivamente ensinados.

Indícios de autonomia didática e de disponibilidade para mudar procedimentos didáticos manifestaram-se na atuação de diferentes professoras ou revelaram-se em momentos específicos. No primeiro caso, recordemos certas opções de atividades muito praticadas por várias delas, como a manutenção de tarefas de cópia ou a busca de exercícios distintos para alunos com rendimentos diferentes que frequientavam a mesma sala. No segundo caso - e levando em conta a inserção voluntária do grupo de docentes na investigação -, cabe enfatizar as evidências de disponibilidade para introduzir propostas que tínhamos discutido nos encontros mensais de formação, que pareciam atender a suas expectativas de praticar um ensino mais sistemático da notação alfabética, no dia-a-dia de suas salas de aula.

Interpretamos que os dados aqui analisados reforçam nosso entendimento de que é na dinâmica da sala de aula que as professoras recriam aquelas orientações do savoir savant e dos textos do saber. O desconhecimento pormenorizado do cotidiano da sala de aula e do perfil das professoras alfabetizadoras por parte dos que geram prescrições (acadêmicos, autores de propostas curriculares e de livros didáticos) constituiria, portanto, um obstáculo para a efetivação de inovações viáveis, que permitam alfabetizar (no sentido estrito de ensinar a notação alfabética) com êxito e, ao mesmo tempo, garantir a iniciação das crianças no mundo da cultura escrita.

\section{Referências bibliográficas}

ARAÚJO, Adriana. Usar ou não usar os novos livros didáticos de alfabetização: concepções e práticas dos professores ao ensinar o 
sistema de escrita alfabética. Dissertação (Mestrado em Educação) - Centro de Educação, Universidade Federal de Pernambuco, Recife, 2004.

CERTEAU, Michel. La culture au pluriel. Paris: Union Générale D’Éditions, 1974.

L'invention du quotidien. 2. ed. Paris: Gallimard, 1990.

CHARTIER, Anne-Marie. Réussite, échec et ambivalence de l'innovation pédagogique: le cas de l'enseignement de la lecture. Recherche et Formation pour les professions de l'éducation. Innovation et réseaux sociaux, INRP, n. 34, p. 41-56, 2000.

. A escola obrigatória e o ofício de ensinar. Palestra proferida no Programa de Pós-Graduação em Sociologia da UFPE, 2002. Mimeografado.

CHEVALLARD, Yves. La transposition didactique: du savoir savant au savoir enseigné. Paris: La Pensée Sauvage, 1985.

DENZIN, Norman; LINCOLN, Yvonna. Handbook of qualitative research. Londres: Sage Publications, 1994.

FERREIRO, Emilia; TEBEROSKY, Ana. Los sistemas de escritura en el desarrollo del niño. México: Siglo XXI, 1979.

MARINHO, Marildes. Discursos sobre a língua nos currículos de final do século. In: BARRETO, Elba S. de Sá et al. (Orgs.). Os currículos do ensino fundamental para as escolas brasileiras. Campinas: Autores Associados; São Paulo: Fundação Carlos Chagas, 1998. p. 43-90.

MORAIS, Artur Gomes de. A apropriação do sistema de notação alfabética e o desenvolvimento de habilidades de reflexão fonológica. Letras de Hoje, Porto Alegre, v. 39, n. 3, p. 175-192, set. 2004. MORAIS, Artur Gomes; ALBUQUERQUE, Eliana Borges Correia. Alfabetização e letramento: o que são? Como se relacionam? Como alfabetizar letrando? In: ALBUQUERQUE, Eliana; LEAL, Telma. Alfabetizando jovens e adultos letrados: outro olhar sobre a educação de jovens e adultos. Belo Horizonte: Autêntica, 2004. p. $59-76$

. Novos livros de alfabetização: dificuldades em inovar o ensino do sistema de escrita alfabética. In: VAL, Maria da Graça Costa; MARCUSCHI, Beth (Orgs.). Livros didáticos de língua portuguesa: letramento e cidadania. Belo Horizonte: CEALE/ Autêntica, 2005. p. 205-236.

MORTATTI, Maria do Rosário Longo. Os sentidos da alfabetização (São Paulo: 1876-1994). São Paulo: Ed. UNESP/CONPED, 2000. MOURA, Dayse Cabral. Por trás das letras: o ensino do sistema de notação alfabética na Educação de Jovens e Adultos. Dissertação
(Mestrado em Educação) - Centro de Educação, Universidade Federal de Pernambuco, Recife, 2001.

OLIVEIRA, Solange Alves. O ensino e a avaliação do aprendizado do sistema de escrita alfabética numa escolarização organizada em ciclos. Dissertação (Mestrado em Educação) - Centro de Educação, Universidade Federal de Pernambuco, Recife, 2004.

SOARES, Magda. Concepções de linguagem e o ensino da língua portuguesa. In: BASTOS, Neusa Barbosa (Org.). Língua portuguesa: história, perspectivas, ensino. São Paulo: EDUC, 1998. p. 53-60.

. Letramento e alfabetização: as muitas facetas. In: REUNIÃO ANUAL DA ANPED, 26., Caxambu, 2003. Anais.. Caxambu: ANPEd, 2003.

VERRET, Michel. Le temps des études. Paris: Librairie Honoré Champion, 1975.

ELIANA BORGES CORREIA DE ALBUQUERQUE, doutora em educação pela Universidade Federal de Minas Gerais (UFMG), é professora do Departamento de Psicologia e Orientação Educacionais da Universidade Federal de Pernambuco (UFPE). Tem desenvolvido pesquisas na área do ensino da língua portuguesa e da alfabetização; é membro do Centro de Estudos em Educação e Linguagem (CEEL). Publicações recentes: Mudanças didáticas e padagógicas no ensino de língua portuguesa: apropriações de professores (Belo Horizonte: Autêntica, 2005); em parceria com MORAIS, Artur e LEAL, Telma organizou: Alfabetização: apropriação do sistema de escrita alfabético (Belo Horizonte: Autêntica, 2005); em parceria com LEAL, Telma organizou: Alfabetização de jovens e adultos em uma perspectiva de letramento (Belo Horizonte: Autêntica, 2004) e Desafios da educação de jovens e adultos: construindo práticas de alfabetização (Belo Horizonte: Autêntica, 2004). Pesquisa em andamento: "A construção/fabricação de práticas de alfabetização em turmas de educação de jovens e adultos", em colaboração com a professora Andréa Tereza Brito Ferreira. E-mail: elianaba@terra.com.br

ANDREA TEREZA BRITO FERREIRA, doutora em sociologia da educação pela Universidade Federal de Pernambuco (UFPE), é professora do Departamento de Educação da Universidade Federal Rural de Pernambuco, é coordenadora do Centro de Estudos de Educação e Linguagem (CEEL). Publicações recentes: "Brésil-France au quotidien de l'école" (Diversité (Montrouge), n. 150 , p. 179-189, set. 2007); em co-autoria com CHARTIER, 
Anne-Marie, "Ler e escrever também é uma questão de gênero" (In: LEAL, Telam Ferraz; ALBUQUERQUE, Eliana Borges Correia de (Orgs.). Desafios da Educação de Jovens e Adultos: construindo práticas de alfabetização. Belo Horizonte: Autêntica, 2005. p. 4662); "Cotidiano escolar: uma introdução aos estudos do cotidiano" (Sociedade em debate, v. 8, n. 3, p. 49-72, dez. 2002); em parceria com ALBUQUERQUE, Eliana Borges e LEAL, Telma Ferraz organizou: Formação continuada de professores: questões para reflexão (Belo Horizonte: Autêntica, 2005). Pesquisa em andamento: "A construção/fabricação de práticas de alfabetização em turmas de educação de jovens e adultos", em colaboração com a professora Eliana Albuquerque.E-mail: atbrito@superig.com.br

ARTUR GOMES DE MORAIS, doutor em psicologia pela Universidad de Barcelona, é pesquisador do Conselho Nacional de Desenvolvimento Científico e Tecnológico (CNPq) e professor da Universidade Federal de Pernambuco (UFPE), onde coordena o grupo de pesquisa Didática da Língua Portuguesa e se dedica às áreas de psicolingüística, ensino e aprendizagem da língua escrita e formação de professores. Publicações recentes: em parceria com ALBUQUERQUE, Eliana Borges e LEAL, Telma Ferraz organizou: Alfabetização: apropriação do sistema de escrita alfabética (Belo Horizonte: Autêntica, 2005); em co-autoria com LEAL, Telma organizou: A argumentação em textos escritos: a criança e a escola (Belo Horizonte: Autêntica, 2006). Pesquisa em andamento: "Práticas de leitura, produção de textos e análise lingüística na escola: que propõem os novos livros didáticos? Que pensam e fazem os professores?".E-mail: agmorais@uol.com.br

Recebido em dezembro de 2007 Aprovado em janeiro de 2008 
Eliana Borges Correia de Albuquerque, Artur Gomes de Morais e Andréa Tereza Brito Ferreira

\section{As práticas cotidianas de alfabetização: o que fazem as professoras?}

Este trabalho buscou analisar como as práticas de alfabetização se têm caracterizado atualmente, tomando como eixo de investigação a "fabricação" do cotidiano escolar por professoras do $1^{\circ}$ ano do primeiro ciclo da prefeitura da cidade do Recife. No campo teórico, apoiamo-nos em dois modelos distintos que analisam a dinâmica da construção/ produção dos saberes escolares: o da transposição didática e o da construção dos saberes da ação. Para registrar como as professoras estavam transpondo as “mudanças didáticas" relacionadas à alfabetização para suas práticas de ensino e como "fabricavam" suas práticas pedagógicas cotidianas, utilizamos a observação de aulas como procedimento metodológico. As práticas das professoras quanto ao ensino do sistema de escrita alfabético foram classificadas em dois tipos: sistemática e assistemática.

Os dados analisados reforçam nosso entendimento de que é na dinâmica da sala de aula que as professoras recriam as orientações oficiais e acadêmicas.

Palavras-chave: alfabetização; cotidiano escolar; prática de professores

\section{The daily practices of literacy: what} do teachers do?

The present study sought to analyse the current traits of literacy practice performed by first grade teachers in public schools in Recife, Brazil. With regard to theoretical considerations, we were inspired by two different models which analyse the dynamics of the production/construction of school knowledge: studies on didactic transposition and those on the construction of the knowledge of action. In order to register how teachers were transposing "didactic changes" related to literacy into their teaching practice and to understand how they "fabricated" their everyday teaching practices, we employed classroom observation techniques. Practices related to teaching the alphabetic writing system were classified in two types: systematic and non-systematic. Our data support the interpretation that it is in classroom dynamics that teachers recreate official and academic prescriptions.

Key words: literacy; daily school practice; teachers' practice

\section{Las prácticas cotidianas de alfabetización}

Este trabajo buscó analizar como las prácticas de alfabetización se han caracterizado actualmente, tomando como eje de investigación la "fabricación" del cotidiano escolar por profesoras del $1^{o}$ año del primer ciclo de la alcaldía de la ciudad de Recife. En el campo teórico, nos apoyamos en dos modelos diferentes que analizan la dinámica de la construcción/producción del saber escolar: el de la transposición didáctica y el de la construcción del saber de la acción. Para registrar como las profesoras estaban transponiendo las "transformaciones didácticas" relacionadas a la alfabetización para sus prácticas de enseñanza y como "fabricaban" sus prácticas pedagógicas cotidianas, utilizamos la observación de las clases como procedimiento metodológico. Las prácticas de las profesoras en cuanto a la enseñanza del sistema de la escritura alfabética fueron clasificadas en dos tipos: sistemática y asistemática. Los datos analizados refuerzan nuestro entendimiento de que es en la dinámica de la sala de clase que las profesoras recrean las orientaciones oficiales y académicas.

Palabras clave: alfabetización; cotidiano escolar; práctica de profesores 